\title{
EFEITOS DA VARIABILIDADE CLIMÁTICA E CENÁRIOS FUTUROS NA BACIA HIDROGRÁFICA DO RIO MUNDAÚ-PERNAMBUCO/ALAGOAS
}

\author{
LIMA, Mariana Caroline Gomes - marianalima.ambiental@gmail.com \\ Universidade Federal de Pernambuco / UFPE
}

SOUZA, Werônica Meira de - weronicameira@gmail.com

Universidade Federal Rural de Pernambuco / UFRPE

MIRANDA, Rodrigo de Queiroga - rodrigo.qmiranda@gmail.com

Universidade Federal de Pernambuco / UFPE

Submetido em: 13/11/2019

Aceito para publicação em: 08/06/2021

Publicado em: 22/06/2021

DOI: http://dx.doi.org/10.5380/abclima.v28i0.70188

\begin{abstract}
RESUMO: Diversos eventos climáticos atuam na região Nordeste do Brasil, do qual, resultam em uma característica do clima da região. Estes eventos extremos são desencadeados em sua grande maioria pelas ações antrópicas ao meio ambiente de forma isolada ou relacionado a fatores ambientais e regionais e ainda sendo influenciados pelos sistemas meteorológicos atuantes, resultando em longos períodos de seca ou chuvas de altas intensidades em um curto período de tempo. Diante desta problemática, o objetivo do presente estudo foi avaliar a influência dos eventos extremos da precipitação pluviométrica e das mudanças climáticas no padrão hidroclimático, bem como verificar os impactos socioeconômicos e ambientais decorrentes dos desastres associados aos eventos extremos (secas e inundações) na bacia hidrográfica do rio Mundaú/PE-AL ao longo do clima presente e futuro. Utilizaram-se para isto dados pluviométricos disponibilizados pelas Agência Pernambucana de Água e Clima- APAC, Agência Nacional de Águas-ANA e pelo Instituto de Nacional de Meteorologia -INMET para 28 municípios durante o período que compreende 01 de janeiro de 1963 até 31 de dezembro de 2017, além de dados de levantamento de desastres, dados socioeconômicos, quadros futuros projetados para o cenário A1B baseados no modelo HadM3 e o índice de risco e vulnerabilidade. Os maiores registos dos impactos dos eventos extremos para a bacia do rio Mundaú/PE-AL foram as estiagens, enxurradas, secas, inundações e alagamentos. para os índices de desenvolvimento os maiores índices de IDH-M foram encontrados na porção sul da bacia do rio Mundaú, enquanto os piores índices pontos isolados. Para os índices de risco a desastres e de vulnerabilidade, as regiões sul/sudeste e extremo norte/noroeste apresentam risco a desastres moderado a muito alto em relação aos eventos extremos, bem como vulnerabilidade alta a muito alta nessas regiões e em algumas localidades da área central da bacia.
\end{abstract}

PALAVRAS-CHAVE: Vulnerabilidade, desastres ambientais, análise de risco.

\section{EFFECTS OF CLIMATE VARIABILITY AND FUTURE SCENARIOS IN THE MUNDAÚ RIVER WATER BASIN - PERNAMBUCO/ALAGOAS}

\begin{abstract}
Several climatic events act in the Northeast region of Brazil, which result in a characteristic of the region's climate. These extreme events are mostly triggered by anthropic actions to the environment in isolation or related to environmental and regional factors and are still influenced by the operating meteorological systems, resulting in long periods of drought or high intensity rains in a short period of time. Given this problem, the objective of this study was to evaluate the influence of extreme events of rainfall and climate change on the hydroclimatic pattern, as well as to verify the socioeconomic and environmental impacts resulting from disasters associated with extreme events (droughts and floods) in the watershed of the Mundaú/PE-AL river along the present and future climate. For this, rainfall data provided by the Pernambuco Agency for Water and Climate - APAC, the National Water Agency - ANA and the National Institute of Meteorology -
\end{abstract}


INMET for 28 municipalities during the period between January 1, 1963 and December 31 were used 2017, in addition to disaster survey data, socioeconomic data, future frameworks projected for the A1B scenario based on the HadM3 model and the risk and vulnerability index. The greatest records of the impacts of extreme events for the Mundaú river basin/PE-AL were droughts, floods, droughts, floods and floods. for the development indices, the highest HDI-M indices were found in the southern portion of the Mundaú river basin, while the worst indices were isolated points. For the disaster risk and vulnerability indices, the south/southeast and extreme north/northwest regions present moderate to very high disaster risk in relation to extreme events, as well as high to very high vulnerability in these regions and in some locations in the area central part of the basin.

KEYWORDS: Vulnerability, environmental disasters, risk analysis.

\section{EFECTOS DE LA VARIABILIDAD CLIMÁTICA Y ESCENARIOS FUTUROS EN LA CUENCA DEL RÍO MUNDAÚ- PERNAMBUCO/ALAGOAS}

RESUMEN: Varios eventos climáticos actúan en la región Nordeste de Brasil, que resultan en una característica del clima de la región. Estos eventos extremos son en su mayoría desencadenados por acciones antrópicas al medio ambiente de forma aislada o relacionados con factores ambientales y regionales y aún están influenciados por los sistemas meteorológicos operativos, resultando en largos períodos de sequía o lluvias de alta intensidad en un corto período de tiempo. Ante esta problemática, el objetivo de este estudio fue evaluar la influencia de eventos extremos de lluvia y cambio climático en el patrón hidroclimático, así como verificar los impactos socioeconómicos y ambientales derivados de desastres asociados a eventos extremos (sequías e inundaciones) en la cuenca del río Mundaú / PE-AL a lo largo del clima presente y futuro. Para ello, se utilizaron los datos de precipitación proporcionados por la Agencia de Pernambuco para el Agua y el Clima - APAC, la Agencia Nacional del Agua - ANA y el Instituto Nacional de Meteorología - INMET para 28 municipios durante el período del 1 de enero de 1963 al 31 de diciembre de 2017, además de datos de encuestas de desastres, datos socioeconómicos, marcos futuros proyectados para el escenario A1B basados en el modelo HadM3 y el índice de riesgo y vulnerabilidad. Los mayores registros de impactos de eventos extremos para la cuenca del río Mundaú / PE-AL fueron sequías, inundaciones, sequías, inundaciones e inundaciones. para los índices de desarrollo, los índices IDH-M más altos se encontraron en la parte sur de la cuenca del río Mundaú, mientras que los peores índices fueron puntos aislados. Para los índices de riesgo de desastres y vulnerabilidad, las regiones sur / sureste y extremo norte / noroeste presentan riesgo de desastres de moderado a muy alto en relación a eventos extremos, así como vulnerabilidad alta a muy alta en estas regiones y en algunas localidades del área central.

PALABRAS CLAVE: vulnerabilidad, desastres ambientales, análisis de riesgos

\section{INTRODUÇÃO}

As secas no Nordeste brasileiro (NEB) faz parte da variabilidade natural do clima da região, que ocorreram no passado e estão ocorrendo no presente diante das evidências apresentadas pelas projeções de mudanças climáticas e que provavelmente continuaram e se intensificaram futuramente (MARENGO et al. 2016).

Sob os efeitos das ações das mudanças climáticas de acordo com Nóbrega et al. (2016), destaca-se o semiárido em que devido as condições de aumento de temperatura e mudanças na precipitação podem se tornar regiões áridas, alterando não só climaticamente a região, mas a fitogeografia, nas práticas econômicas e sociais. Este quadro alarmante foi observado também por Oyama e Nobre (2003), em estudo elaborado para a Caatinga, em que 
observaram que este bioma está entre os mais vulneráveis em um cenário de aumento das temperaturas globais, o que classifica o NEB em estado de alerta, uma vez que a vulnerabilidade deste bioma aos efeitos das mudanças climáticas representa uma pressão para a desertificação na região.

De acordo com Silva et al., (2017), as projeções apresentadas pelo Painel Intergovernamental de Mudanças Climáticas-IPCC, e literaturas correlatas, atestam mudanças no comportamento atmosférico com tendência a o aquecimento global. Estas mudanças segundo Luque et al., (2013), influenciam diversos setores da sociedade, dentre eles, setores econômicos, sociais e ambientais. Esta hipótese é sustentada por Delazeri et al., (2018), em que estas mudanças climáticas ocorrentes no NEB podem ampliar ainda mais a vulnerabilidade de agricultores que, historicamente, enfrentam dificuldades ambientais e sociais, ampliando as desigualdades regionais, visto que as frequentes secas ocorrentes no período chuvoso, dependendo da intensidade e duração, provoca redução da produção em áreas da agricultura familiar, impactos ambientais e promovem migrações de famílias para áreas urbanas (HAGENLOCHER et al., 2019; MEZA et al., 2019).

Para Freitas et al., (2014), estes eventos climáticos extremos são desencadeados em sua maioria pela ação antrópica ao meio ambiente, isoladamente ou estes fatores associados aos fatores ambiental ou regional e ainda influenciados por sistemas meteorológicos que atuam de forma isolada ou combinada, geralmente associados às chuvas de altas intensidades ou sua ausência que resultam em inundações ou secas, como observado por Marengo et al., (2016). Estes eventos climáticos extremos foram também observados por Moura et al., (2016), em que no NEB, os desastres hidrológicos como enxurradas, inundações bruscas ou graduais e alagamentos foram impulsionados por eventos de chuvas intensas, chuvas estas que representaram valores iguais ou superiores a $60 \mathrm{~mm} /$ dia e de chuvas consideradas extremas que representa igual ou superior a $100 \mathrm{~mm} / \mathrm{dia}$.

Ao analisar os períodos de seca, este fenômeno não ocorre de forma homogênea, como visto em estudo elaborado por Tavares et al., (2019), ocorrendo anos de seca total, resultando em efeitos observados em toda a região e secas parciais, em que atinge apenas algumas áreas, entretanto, estas secas contribuem significativamente para a o agravamento da desertificação na região semiárida.

Esta irregularidade das chuvas representa um dos obstáculos constantes para o desenvolvimento das atividades agropecuárias, e o armazenamento de água que está presente na mão de poucos, intensifica ainda mais os efeitos sociais (MARENGO, 2010).

Diante disso, diversos órgãos ligados à meteorologia no Brasil utilizam métodos diversos para quantificar os efeitos climáticos, dentre eles, a simulação do clima passado, presente e futuro quantificado através de códigos computacionais que representam equações matemáticas que regem os movimentos atmosféricos e as interações com a superfície (NEUHAUS, 2017).

De acordo com o Global Change Master Directory da NASA, o modelo HadCM3 desenvolvido no ano de 1999, é um dos principais modelos utilizados, servindo de suporte informacional para os Relatórios de Avaliação do IPCC. Este modelo é acoplado oceano-atmosfera desenvolvido no Hadley Centre, UK 
Meteorological Office, da Grã-Bretanha e não precisa de ajustes nos fluxos de energia no oceano para produzir uma boa simulação.

Neste contexto, considerando que a maioria dos estudos climáticos tem enfatizado apenas as análises das anomalias de precipitação, este trabalho tem como objetivo avaliar a influência dos eventos extremos da precipitação pluviométrica e das mudanças climáticas no padrão hidroclimático, bem como verificar os impactos socioambientais decorrentes dos desastres associados aos eventos extremos (secas e inundações) na bacia hidrográfica do rio Mundaú ao longo do clima presente e futuro, utilizando o modelo regional ETA. Proporcionando informações que podem servir de base no monitoramento dos padrões hidroclimáticos caso alterações semelhantes venham a ser observadas.

\section{MATERIAL E MÉTODOS}

\subsection{CARACTERIZAÇÃO DA ÁREA DE ESTUDO}

A bacia hidrográfica do rio Mundaú compreende os estados de Pernambuco e Alagoas, possuindo as coordenadas $8^{\circ} 42^{\prime}$ e $9^{\circ} 36^{\prime}$ de latitude Sul e 36039' e 35047' de longitude Oeste (Figura 1), a bacia ocupa uma área de $4.101,90 \mathrm{~km}^{2}$ e abrange 16 munícipios do Estado de Pernambuco e 17 municípios do Estado de Alagoas (GOMES et al., 2014).

Segundo Alvares et al. (2014), a classificação climática de Köppen (1931), é a mais utilizada em todo o mundo, por critérios geográficos e climáticos. Conforme essa classificação, o clima da BHRM, se mescla entre os tipos: As (clima tropical com estação seca de verão), Am (clima de monção), Csa (clima temperado húmido com verão seco e quente) e Csb (clima temperado húmido com verão seco e temperado), com predominância do tipo As sobre os demais (SILVA et al., 2018).

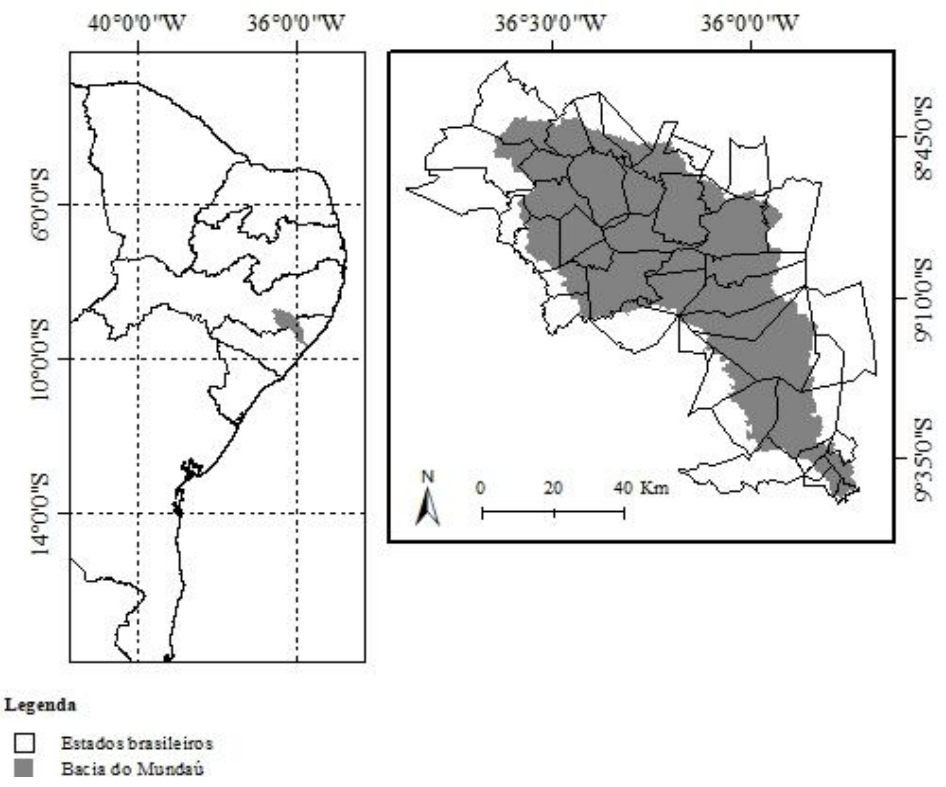

Figura 1- Localização geográfica da bacia hidrográfica do rio Mundaú.

As principais estruturas geológicas que formam a bacia são: Planalto da Borborema; Depressão Periférica da Borborema e Depósitos Sedimentares do 
Quartenário, também classificado os principais tipos de solos da BHRM como: argissolos; gleissolos; latossolos; neossolos litólicos; neossolos regolíticos; planossolos e solos indiscriminados de mangue GOMES et al., (2016).

\subsubsection{DADOS PLUVIOMÉTRICOS}

O levantamento dos dados de precipitação pluviométrica diária para a bacia do Mundaú de 01 de janeiro de 1963 até 31 de dezembro de 2017, foram obtidos através das estações monitorados pela Agência Pernambucana de Água e Clima- APAC, Agência Nacional de Águas-ANA e pelo Instituto de Nacional de Meteorologia -INMET para 28 municípios destacados na tabela 1.

Tabela 1 - Municípios analisados e suas respectivas séries históricas.

\begin{tabular}{|c|c|c|}
\hline Município & Período de Falhas & Série Histórica \\
\hline Angelim - PE & - & 1993 a 2017 \\
\hline Brejão - PE & 1980,1987 a 1992, 2007, 2009 & 1962 a 2017 \\
\hline Bom Conselho - PE & $\begin{array}{c}1982 \text { a } 1984,1985 \text { a } \\
1992,2000,2003,2004,20111\end{array}$ & 1962 a 2017 \\
\hline Caetés - PE & $\begin{array}{c}1964,1965,1972,1973,1981,1990- \\
2000,2008,2011\end{array}$ & 1963 a 2017 \\
\hline Calçado - PE & - & 1963 a 2017 \\
\hline Capoeiras - PE & - & 1963 a 2017 \\
\hline Capela - PE & _ & 1963 a 2017 \\
\hline Chã Preta - PE & - & 1963 a 2017 \\
\hline Canhotinho - PE & $1992,2003,2004,2006$ & 1963 a 2017 \\
\hline Garanhuns - PE & $1969,1970,1989-1992$ & 1963 a 2017 \\
\hline Palmeirina - PE & - & 1963 a 2017 \\
\hline Jucati - PE & $1999,2003,2004,2006$ & 1963 a 2017 \\
\hline Jurema - PE, & - & 1963 a 2017 \\
\hline Jupi - PE & - & 1963 a 2017 \\
\hline Lagoa do Ouro PE & - & 1963 a 2017 \\
\hline $\begin{array}{l}\text { São João - PE } \\
\text { Satuba - PE }\end{array}$ & $\begin{array}{l}- \\
-\end{array}$ & $\begin{array}{l}1963 \text { a } 2017 \\
1963 \text { a } 2017\end{array}$ \\
\hline Atalaia - AL & - & 1963 a 2017 \\
\hline
\end{tabular}


Branquinha - AL

Jan a Dez de 1992, Mar de 1993 a

Dez de 1994 Mar 1994 a Ago de

Rio Largo - AL

Ibateguara- AL

Maceió - AL

Messias - AL

Murici - AL

União dos Palmares -

$\mathrm{AL}$

Pilar - AL

São José da Laje -AL

Santana do Mundaú -

$\mathrm{AL}$
1996, Nov de 1996, Mar a Ago 1997

1963 a 2000

1963 a 2017

1963 a 2017

1963 a 2017

1963 a 1966,1969 a 1992

1963 a 2017

1915 a 1991

1063-2017

1991 a 2017

Dez de 2010

1991 a 2017

Fonte: Elaborado por Mariana Caroline Gomes de Lima (2018).

Vale ressaltar que devido a indisponibilidade de dados e a presença de falhas, outras estações com uma série de dados menores foram consideradas, diante da necessidade em analisar uma série histórica com o mesmo período, acrescentando os municípios de Atalaia ( $A L)$, Branquinha ( $A L)$, Calçado $(P E)$, Capoeiras (PE), Capela (PE), Chã Preta (PE),Ibateguara ( $A L)$, Jupi (PE), Jurema $(P E)$, Lagoa do Ouro (PE), Maceió ( $A L)$, Messias ( $A L)$, Palmeirina (PE), Pilar ( $A L)$, São João (PE) e Satuba (PE).

Foram adquiridos os cenários climáticos da precipitação pluviométrica total anual dos anos de 2025 e 2055 para o cenário A1B, junto ao Centro de Previsão de Tempo e Clima do Instituto Nacional de Pesquisas Espaciais (CPTEC/INPE).

\subsection{DESASTRES E IMPACTOS ASSOCIADOS AOS EVENTOS EXTREMOS}

Foi realizado o levantamento dos dados de desastres (secas, estiagem, alagamentos, inundações, afetados, desabrigados, desalojados, deslocados e óbitos) decorrentes dos extremos climáticos, dos 30 municípios que compõem a bacia do rio Mundaú no período de 1961 a 2017, por meio de Decretos, Portarias (atos administrativos) e Avadan (avaliação de danos), fornecidos pelo Sistema Integrado de Informações sobre Desastres (S2ID) do Ministério da Integração Nacional.

Para avaliar os impactos associados aos eventos extremos de precipitação (chuvas e ausência de chuvas), foram contabilizados os desastres registrados no período de 1961 a 2017 na bacia do rio Mundaú referentes às chuvas, a saber: inundação, enxurrada, alagamento e erosão de margem pluvial; os desastres decorrentes da ausência de chuvas (secas), que correspondem aos registros das secas e estiagem; e os desastres totais, que equivalem a contabilização dos desastres associados às chuvas, secas, doenças infecciosas e processos de erosão registrados no MIN. Também foi realizado o 
somatório do número de óbitos, pessoas afetadas, desalojadas, desabrigadas e descoladas para o mesmo período.

Em seguida, foram elaborados mapas com identificação dos municípios com registros de desastres decorrentes das chuvas, secas, desastres totais, e óbitos ao longo da bacia. A partir do levantamento do número de pessoas afetadas, desalojadas, desabrigadas e deslocadas de 1961 a 2017 foi elaborada uma tabela destacando os municípios onde ocorreram esses registros.

\subsection{DADOS SOCIOECONÔMICOS}

Também foram utilizados dados do censo de 2010 do Instituto Brasileiro de Geografia e Estatística-IBGE referente às variáveis densidade demográfica, renda percapita média, população total, índice de desenvolvimento humano, condições de habitabilidade, e acesso das pessoas a serviços básicos para os 30 municípios da bacia do rio Mundaú.

\subsection{CENÁRIOS CLIMÁTICOS FUTUROS}

Para gerar cenários para a bacia hidrográfica do rio Mundaú, foram adquiridos no Centro de Previsões do Tempo e Estudos Climáticos (CPTEC,INPE) os cenários climáticos correspondentes aos períodos de 2025 e 2055 para o cenário A1B para Pernambuco. Estes cenários são baseados no modelo HadCM3, e gera condições de contorno e fornece condições para o modelo regional ETA.

O modelo ETA inclui o aumento dos níveis de concentração de $\mathrm{CO}_{2}$ conforme o cenário de emissão. Este modelo reproduz o cenário A1B do IPCC SRES, fornecido pelo modelo global acoplado oceano-atmosfera HadCM3, em quatro membros (versões) de perturbação do modelo global (sem perturbação CNTRL; baixa sensibilidade - LOW; média sensibilidade e - MID; alta sensibilidade - $\mathrm{HIGH}$ ).

\section{5. Í́NDICES DE RISCO E DE VULNERABILIDADE}

Para determinar os índices de risco à desastre e de vulnerabilidade da população frente aos eventos extremos foi utilizada a equação de Risco Meira (2 e 3) (Souza et al. 2015), que é função dos desastres associados às variações climáticas e dos indicadores socioeconômicos:

$$
\begin{aligned}
& R=\frac{P(D D+R M+P T+H)}{I D H} \\
& V=D D+R M+P T+H
\end{aligned}
$$

Em que, R: risco a desastre; $\mathrm{P}$ : perigo, expresso pelo número de desastres registrados em função das variabilidades climáticas (desastres associados às chuvas e as secas); DD: densidade demográfica, que é obtido a partir da razão entre a população residente total e a área da cidade $\left(\mathrm{hab}, \mathrm{km}^{2}\right)$; $\mathrm{RM}$ : renda percapita média; PT: população total existente; $\mathrm{H}$ : condições de habitabilidade, 
e o acesso das pessoas a serviços básicos nas cidades; IDH: índice de desenvolvimento humano, obtido pela média aritmética de três sub-índices, referentes às dimensões Longevidade (IDH-L), Educação (IDH-E) e Renda (IDHR). Os dados das variáveis DD, RM, PT e IDH correspondem ao censo de 2010 do IBGE, e os registros de desastres foram obtidos por meio do Ministério da Integração Nacional para 30 municípios no período de 1961 a 2017.

A partir da equação de Risco Meira foram obtidos os índices de risco e de vulnerabilidade nos municípios que compõe a bacia do rio Mundaú, e confeccionados os mapas desses índices, assim como os mapas da população, renda, DD, IDH, IDH-L, IDH-E e IDH-R através do software ArcGis-9.3. Adotaram-se quatro classes: baixa, média, alta e muito alta, definidas pelo método do Desvio Quartílico, conforme Ramos e Sanchez (2000).

\section{RESULTADOS E DISCUSSÃO}

A distribuição temporal da climatologia da precipitação pluviométrica mensal (Figura 2), que corresponde a média aritmética mensal da precipitação de 1961 a 2017 das estações pluviométricas da bacia do rio Mundaú, demonstra que o período úmido corresponde ao período de março a julho, com destaque para o meses mais chuvosos (abril, maio, junho e julho) com valores médios acima de $500 \mathrm{~mm}$ nesse quadrimestre, onde concentra $56 \%$ do total anual. De acordo Lacerda, Ferreira e Souza (2006), as Ondas de Leste e a Zona de Convergência Intertropical são os principais sistemas meteorológicos responsáveis pelas chuvas nesse quadrimestre. O período seco concentra-se entre os meses de setembro a fevereiro, com valores médios mensais entre 20 e $60 \mathrm{~mm}$.

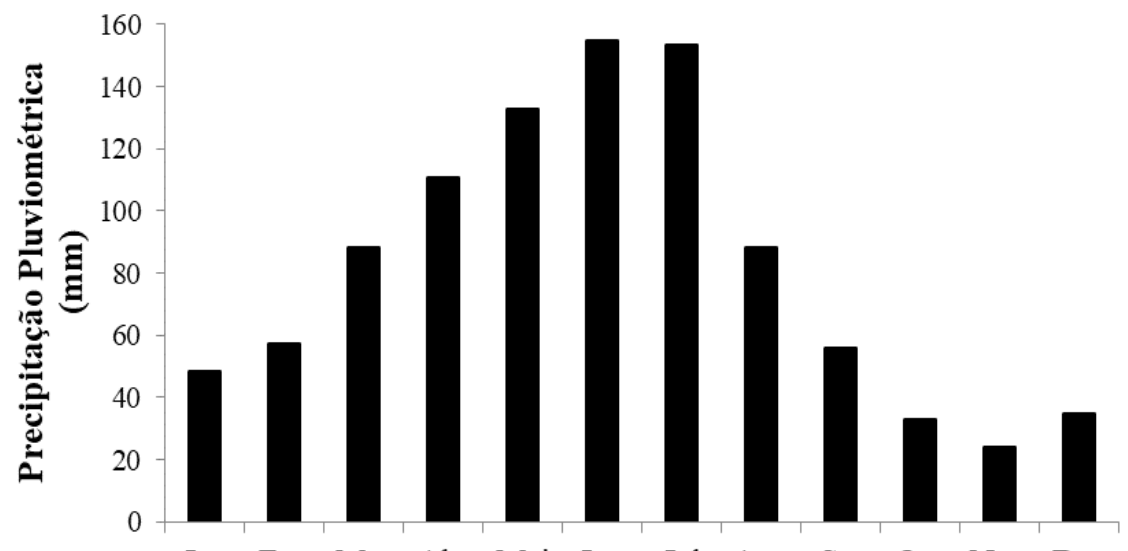

Jan Fev Mar Abr Mai Jun Jul Ago Set Out Nov Dez

Figura 2- Climatologia da precipitação pluviométrica mensal para a bacia do rio Mundaú durante o período de 1963 a 2017. Fonte: APAC 2018.

\subsection{IMPACTOS OCASIONADOS PELOS EVENTOS EXTREMOS}

Ao analisar o número de eventos na figura 3 , observa-se que os municípios apresentam uma baixa infraestrutura, e que a maioria das áreas residências em virtude das condições econômicas, é localizada em áreas com 
baixo valor imobiliário e sujeitas a riscos diversos já que compartilham proximidades as áreas vulneráveis.

De acordo com a Figura 3, foram registrados 198 casos de estiagem, 62 de enxurradas, 45 de secas, 22 de inundações, 6 de alagamentos e 2 casos de tempestades locais. Verifica-se também que o maior número de eventos é nos municípios localizados no estado de Pernambuco, dentre eles, destacam-se os municípios de Caetés-PE, Garanhuns-PE, São João-PE, Brejão-PE, Capoeiras-PE e Lajedo-PE que apresentaram para o período de estudo um total de 20, 20, 17, 16,15 e 15 eventos climáticos devastadores.

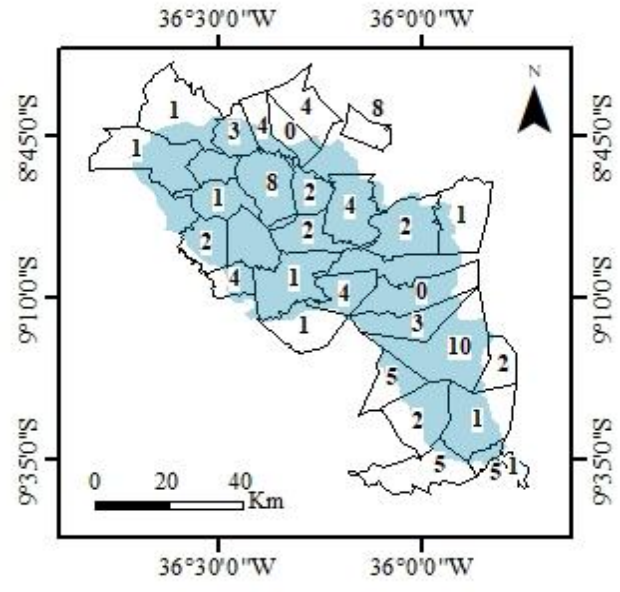

(a)

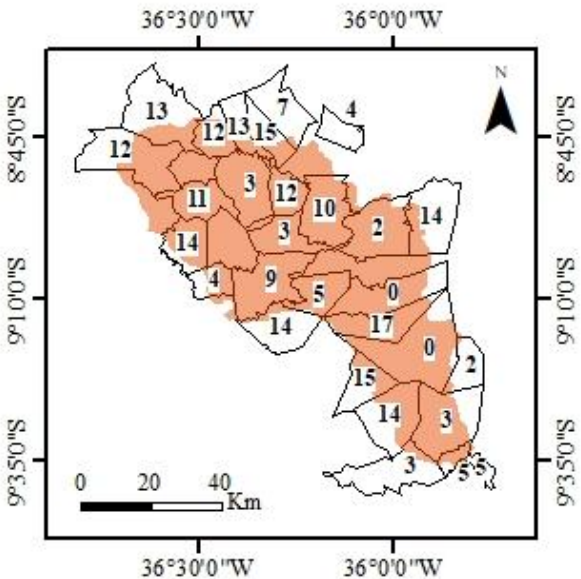

(b)

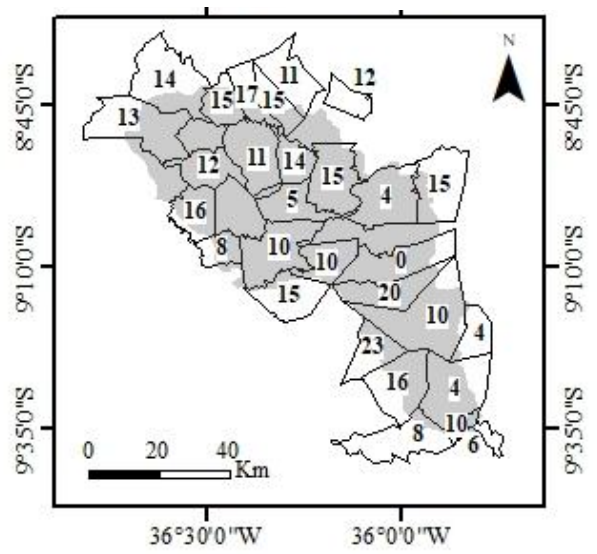

(c)

Figura 3- Número de desastres registrados associados às chuvas (a), secas (b) e desastres total (c) no período de 1963 a 2017 para a bacia do rio Mundaú. Sistema Integrado de Informações sobre Desastres (S2ID)-2018

No município de Angelim-PE os riscos levaram à zona rural a elevados riscos agrícolas e pecuária, representada pela queda na produtividade nas produções de milho, feijão mulatinho, e feijão de corda e a produção de carne e leite na região. No ano de 2012 o município sofreu com a baixa significativa no índice pluviométrico do qual resultou em quatro meses de escassez de água, resultando em $90 \%$ de perda das pastagens, $50 \%$ da produção de leite e na pecuária de corte $20 \%$, representando um prejuízo total de $\mathrm{R} \$: 50.000$ reais. 
Alunos ficaram sem aulas principalmente moradoras da zona rural em que devido às péssimas estruturas das estradas. Fez-se necessário o aumento da capacidade dos reservatórios hídricos, devido à dificuldade no abastecimento de água para o uso doméstico.

Em Caetés-PE medidas de assistência e recuperação econômica e social foram julgadas necessárias, visto que foram notados riscos potenciais a integridade física da população. Em 1998 o fenômeno climático "El Niño" ocasionou miséria e fome para a população da zona rural, em contrapartida, onze anos após, em 2009, os altos índices pluviométricos no mês de junho resultou em perda da safra que foi de 3.022 toneladas, prejuízos na pecuária com cerca de 600 animais afetados e rompimento de barragens. Em 2012 as reservas de água foram afetadas causando sérios riscos à população e o mesmo evento foi observado em Lajedo.

As intensas precipitações ocasionaram alagamentos em diversas ruas da cidade de Palmeirina, causando desabamento de diversas residências, destruição de estradas e bueiros, impossibilitando o tráfego de veículos. Em março de 2005 o município sofreu com as intensas precipitações que superaram a $90 \%$ da média histórica.

São João-PE apresentou mananciais com baixos volumes e entre os anos de 2008 e 2009 ocorreram quedas nas reservas hídricas, resultando na escassez de água potável para abastecimento humano e animal.

A estiagem persistente foi grande característica do município de Lagoa do Ouro-PE em que esta condição climática tornou dramática para a população, resultando na retração econômica provocando êxodo rural. Setores como transporte público, aulas, escoamento de produções foram impactadas ao longo do estudo. O mesmo ocorreu para o município de Capoeiras.

A quadra invernosa no município de Jucati-PE apresentou baixas precipitações de dezembro de 2001 a janeiro de 2002, comprometendo os mananciais de abastecimento de água bem como também no município de JupiPE. Em Jurema-PE o transbordamento de rios e riachos fugiu da normalidade climatológica da região, causando diversos danos e prejuízos à população local.

Em Calçado-PE as chuvas não conseguiram encher os reservatórios em 2002 enquanto que em 2008 os altos índices pluviométricos no mês de março superaram a média histórica ( $278 \mathrm{~mm}$ quando a média histórica era de $82 \mathrm{~mm}$ ), acarretando danos e prejuízos ao município. Enquanto que os anos posteriores houve redução na precipitação para níveis inferiores aos da normal climatológica. Estes baixos níveis de precipitação foram também verificados em Canhotinho que de janeiro a maio de 2012 houve uma redução de $75 \%$ com relação ao ano de 2011 e $50 \%$ com relação ao ano de 2010 . O mesmo quadro de secura foi observado por Marengo et al. (2016), em que entre os períodos de 2011 a 2014 o semiárido Nordestino apresentou uma grande área com deficiência hídrica, áreas onde o balanço hídrico foi negativo em razão da falta de chuvas, temperaturas elevadas e secura do ar.

As enchentes e maior intensidade das chuvas em Garanhuns resultaram em perdas animais, isolação de rodovias como a PE-120 e 123 por queda de barreira e por níveis de água superiores em seu leito em 1984 e como observado em 1992 acarretando em graves consequências social e econômica. Perda de lavoura e pastagens foi provocada pela baixa e irregularidade 
pluviométrica em 2003 enquanto que em 2008 o excesso de chuva durante a época de colheita resultou em perda de mais de $60 \%$ na produção esperada de feijão e $80 \%$ na produção de milho.

Perda agrícola que se refletiu diretamente na economia do município foi também observada em Brejão-PE em que a estiagem em 2001 resultou em 90\% da safra e a pecuária de leite sofreu perdas em função da secagem da pastagem. Em 2003 e 2004 a safra de grãos foram 50\% menos em função da não formação de pastagem e a safra de manga e caju foram prejudicadas pela ocorrência de chuva, pois favoreceu o ataque de insetos, frustrando $70 \%$ da safra em 2004.

Em Murici-AL, transbordamento de rios e deslizamento de encostas em 1989 resultou em um quadro de calamidade pública e situação de desespero da população humilde. Os péssimos indicadores sociais, a economia deficitária, o precário abastecimento de água potável e saneamento básico refletiram em incalculáveis prejuízos ao município e a sua população. Em 2010 os moradores da zona rural e urbana ficaram sem condição de deslocamento e sem comunicação, abastecimento de água potável e energia elétrica, sem acesso às escolas, postos de saúde e creches foram destruídas pela força das águas.

Transbordamento de rios e deslizamento de encostas também ocorreu em União dos Palmares-AL, São José da Laje-AL, Satuba-AL, Rio Largo-AL, PilarAL, Atalaia-AL, Capela-AL e Maceió-AL em 1989 com desabamento de casas e vitimam fatais e consideráveis contingentes de desabrigados. Em 1993 os efeitos danosos decorrente do longo período de estiagem dizimaram o gado e a lavoura. Na zona rural inúmeras famílias se retiraram de suas residências a procura de alimentos para suprir suas necessidades, causando aumento no quadro do êxodo rural. No ano de 2000 as fortes chuvas, seguidas de enchentes, abateram sobre o município nos últimos dias de julho, causando desabamento de casas, deslizamentos de barreiras, ruas danificadas e abastecimento de água e energia prejudicado.

Em 2010 o transbordamento dos rios Mundaú, Canhoto e Mirim, causaram danos e prejuízos à população. Enquanto que no ano de 2013 o baixo índice pluviométrico causou seca de açudes, riachos e nascentes prejudicando a safra de cana-de-açúcar, banana, laranja, abacaxi, macaxeira, inhame, feijão de corda e outras culturas produzidas neste município. Em São José da Laje-AL fortes chuvas interruptas de aproximadamente 12 horas causaram alagamento, desmoronamento de barreiras e destruição e danificação de casas, prédios públicos, comercio e pavimento em maio de 2009 e abril de 2010.

Em Santana do Mundaú-AL a ausência de chuvas a vários meses provocou a perda de lavouras de forma irrecuperável, impedindo aos animais o acesso à água, dizimando pequenos rebanhos e a produção de laranja (principal produto agrícola do município) foi perdido cerca de $50 \%$ da sua produção. Em 2012 a baixa pluviosidade durante os meses de setembro a dezembro e janeiro a abril de 2013 comprometeram a produção de produtos de origem agropecuária em todo o município e em Branquinha-AL, e a perda de laranja lima foi de $60 \%$ com o esgotamento hídrico das plantas, formação irregular dos frutos e consequentemente perda da produtividade.

Em Chã Preta-PE os péssimos indicadores sociais, a economia deficitária e precário abastecimento de água potável e saneamento básico do município 
auxiliaram o quadro de destruição oriunda das fortes chuvas que caíram no mês de julho de 2010. Em 2013 a seca refletiu na diminuição das vazões de córregos e riachos além do desaparecimento de nascentes. A economia por sua vez sofreu com a redução do volume de vendas de produtos agropecuários e no comercio de estabelecimentos localizados tanto na zona urbana como na zona rural.

Em 2000 no município de Messias-AL, a ausência de um sistema de alerta e alarme de nível estatual com dificuldade de contato com municípios vizinhos em virtude da ocorrência de danos aos sistemas de comunicação e da interrupção de rodovias por queda de barreiras, pontes e alagamentos dificultou o socorro às vítimas enquanto que em 2008 este efeito ocasionado pelas chuvas intensas ocorreu durante 36 horas, repetindo o quadro de inundação e deslizamento de encostas.

Em 2009 as chuvas interruptas que atingiram o município de Capela-PE de aproximadamente 24 horas de duração, causaram desabamento de encostas, destruição e danificações de casas, estradas e pontes. Foram atingidas cabeceiras de pontes, obras de artes, e estradas danificadas em uma extensão de $120 \mathrm{~km}$, as quais serviam de acesso de transporte de alunos da rede municipal. Em 2012 como observados nos municípios citados acima, houve escassez de chuvas, incluindo o período historicamente considerado como quadra chuvosa no município. Em consequência disso verificou-se uma perda na produção agrícola e pecuária, visto que a principal fonte de produção do município é a cana de açúcar e criação de gado. Registrou-se também a redução de águas nos açudes das fazendas, que é a principal fonte de abastecimento rural. O baixo nível do Rio Paraíba deixou algumas localidades sem água corrente e o esgotamento das águas de poços, cacimbas devido ao baixo nível dos lençóis freáticos.

Verifica-se que a associação entre características de infraestrutura e a falta ou a elevados extremos de precipitação, resultam em danos irreparáveis, como observado por Moura (2011). Desta forma, é digno ilustrar os óbitos registrados nos municípios que compõe a bacia do Rio Mundaú oriundos dos desastres associados aos eventos climáticos de 1963 a 2017, conforme a figura 4. Para o período analisado foram contabilizadas 31 mortes.

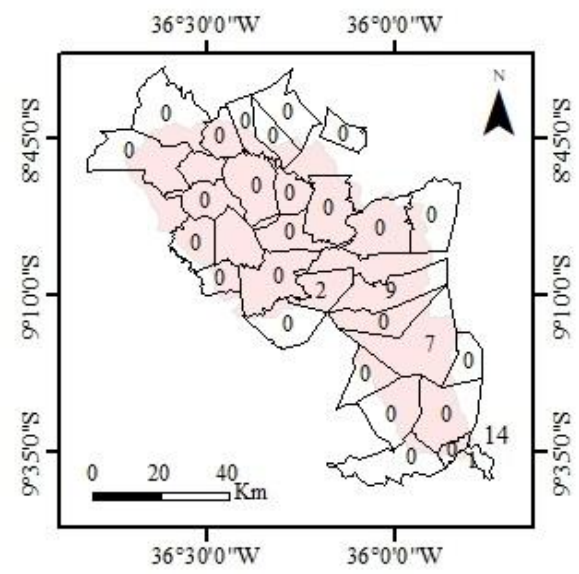

Figura 4- Número de óbitos registrados entre 1963 a 2017 nos municípios que compõe a bacia hidrográfica do Rio Mundaú. Sistema Integrado de Informações sobre Desastres (S2ID)-2018. 
De acordo com Freitas et al. (2012), em média 102 milhões de pessoas são afetadas por enchentes a cada no mundo, e 366 mil por deslizamento de terra, secas e estiagens representam um total de 558 mil vidas. Cabe ressaltar que dessas mortes, 14 foram registradas na região metropolitana de Maceió-AL.

O deslocamento de famílias para outras localidades é verificado em trabalho realizado por Valencio (2005), quando os riscos de colapso das obras civis são classificados como alto pela Defesa Civil ou quando a degradação já ocorreu, por sua vez, colocam-no na condição de desalojado - quando permitem compartilhar a moradia com parentes ou amigos, ou desabrigados - quando por motivos diversos, as alternativas citadas anteriormente são obrigadas a fixar-se temporariamente em abrigos públicos.

Assim, é oportuno destacar o número de famílias desalojadas e desabrigadas no período de 1963 a 2017 nos municípios que compõe a bacia do Rio Mundaú (Tabela 2), revelando a necessidade do monitoramento das áreas propícias a desastres e organização pública.

Tabela 2- Número de eventos registrados no período de 1961 a 2017 para os municípios da bacia do Rio Mundaú evidenciando o número de pessoas afetadas, desalojadas, desabrigadas e deslocadas.

\begin{tabular}{|c|c|c|c|c|c|}
\hline Municípios & Afetadas & Desalojadas & Desabrigadas & Deslocados & Total \\
\hline Angelim (PE) & 14688 & & & & 14688 \\
\hline Brejão (PE) & 32368 & & & & 32368 \\
\hline Caetés (PE) & 203151 & & & & 203151 \\
\hline Calçado (PE) & 37384 & 45 & 45 & 10 & 37484 \\
\hline Canhotinho (PE) & 29365 & & & & 29365 \\
\hline Capoeiras (PE) & 60136 & & & & 60136 \\
\hline Correntes (PE) & & 2330 & 233 & & 2563 \\
\hline Garanhuns (PE) & 63538 & & & & 63538 \\
\hline Jucati (PE) & 15810 & & & & 15810 \\
\hline Jupi (PE) & 34542 & 118 & 46 & & 34706 \\
\hline Jurema (PE) & 27856 & & & & 27856 \\
\hline Lagoa do Ouro (PE) & 8823 & & & & 8823 \\
\hline Lajedo (PE) & 112322 & & & & 112322 \\
\hline Palmeirina (PE) & 9711 & & & & 9711 \\
\hline São João (PE) & 43477 & 214 & & 60 & 43751 \\
\hline Atalaia (AL) & 350 & 4810 & 116 & & 5276 \\
\hline Branquinha ( $A L)$ & 5490 & 3200 & 1000 & & 9690 \\
\hline Capela (AL) & 21966 & 100 & 300 & & 22366 \\
\hline Chã Preta (AL) & 7564 & & & & 7564 \\
\hline Ibateguara (AL) & 15863 & & & & 15863 \\
\hline Maceió (AL) & & 540 & 1090 & 210 & 1840 \\
\hline Messias (AL) & 500 & & & & 500 \\
\hline Murici (AL) & 1235 & 10000 & 5000 & & 16235 \\
\hline Pilar (AL) & & & & & 0 \\
\hline Rio Largo (AL) & 567 & 185 & 184 & & 936 \\
\hline $\begin{array}{l}\text { Santana do Mundaú } \\
\text { (AL) }\end{array}$ & 862 & 3750 & 500 & & 5112 \\
\hline São José da Laje (AL) & 1039 & 5100 & 541 & 520 & 7200 \\
\hline Satuba $(A L)$ & & 905 & 200 & & 1105 \\
\hline $\begin{array}{l}\text { União dos Palmares } \\
(\mathrm{AL})\end{array}$ & 1872 & 20000 & 9453 & 415 & 31740 \\
\hline
\end{tabular}

Fonte: Sistema Integrado de Informações sobre Desastres (S2ID)-2018 e modificado por Mariana Caroline Gomes de Lima (2018). 
Observa-se na figura 5 que dentre os municípios, a região pertencente ao estado de Alagoas são as áreas mais impactadas pelos efeitos das chuvas em que se verifica que em União dos Palmares houve o desalojamento de 20.000 mil famílias, Murici-AL 10.000 mil e em Atalaia 4.810 mil famílias e o número de desabrigados superaram o número de 9.453 mil famílias em União dos Palmares. Ao analisar os municípios pertencentes ao estado de Pernambuco ficam evidentes que o número de famílias desalojadas foi maior em Correntes, com 2.330 mil famílias desalojadas e o menor registro no município de Calçado$\mathrm{PE}$ enquanto que o número de desabrigados foi maior em Correntes com 233 famílias desabrigadas e o menor em Calçado-PE com 45 famílias desabrigadas.

Ressalta-se, portanto, que não é de hoje que as pessoas convivem com esses riscos, e o crescimento urbano desordenado, expõe à comunidade aos desastres que por sua vez ultrapassam os limites de tolerância nos planos social e ambiental. Sirvinskas (2018), relata que as mudanças climáticas causarão deslocamento maciço de populações que atualmente encontram-se vivendo em áreas de riscos e há necessidade de haver políticas públicas adequadas para acolher os deslocados ambientais ou climáticos.

Em estudo elaborado por Augustin et al. (2014), a qualidade de vida é altamente dependente das variáveis relacionadas à ocupação do meio físico e sua densidade populacional, portanto, observa-se na Figura 15, que os maiores índices de IDH-M são observados na porção sul da bacia do rio Mundaú (0.6110.721 ) que compreende os municípios de Rio Largo, Maceió e Pilar com IDH-M de (0.575-0.611). Ao observar a porção norte da bacia verifica-se que Garanhuns-PE apresenta o maior IDHM de (0.611-0.721). Por outro lado, os piores índices $(0.000$ - 0.527) foram observados em pontos isolados na bacia que são eles: Lagoa do Ouro-PE, Murici-AL, Ibateguara-AL, Branquinha-AL, São João-PE e Jurema-PE. 


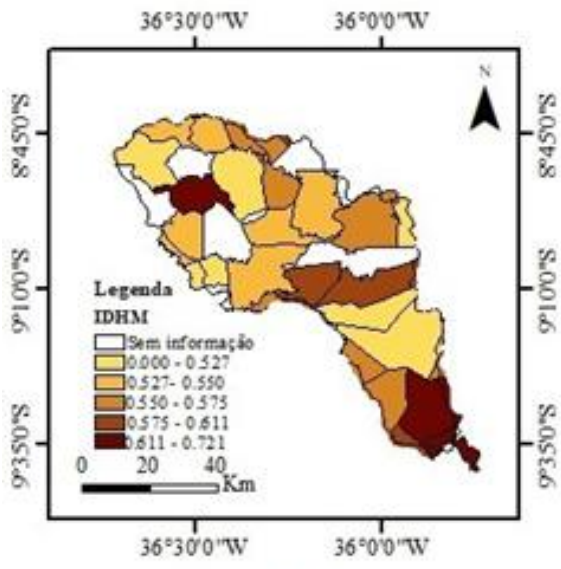

(a)

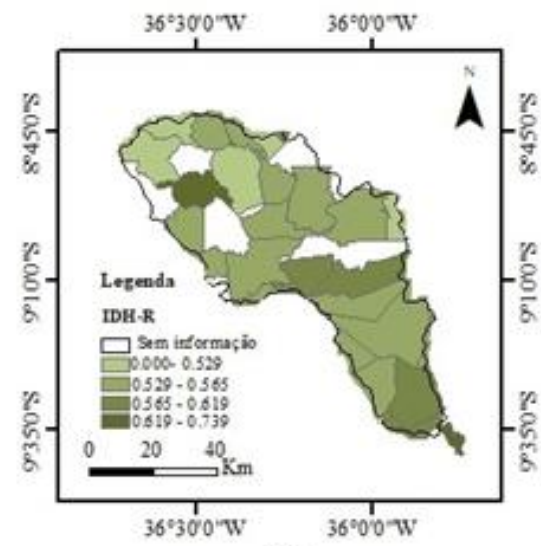

(c)

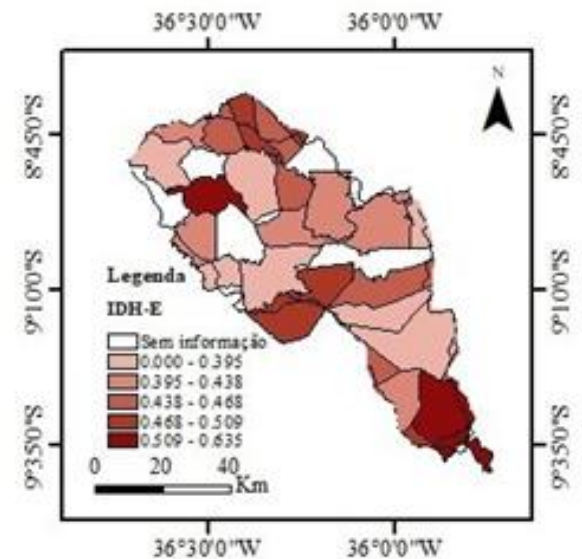

(b)

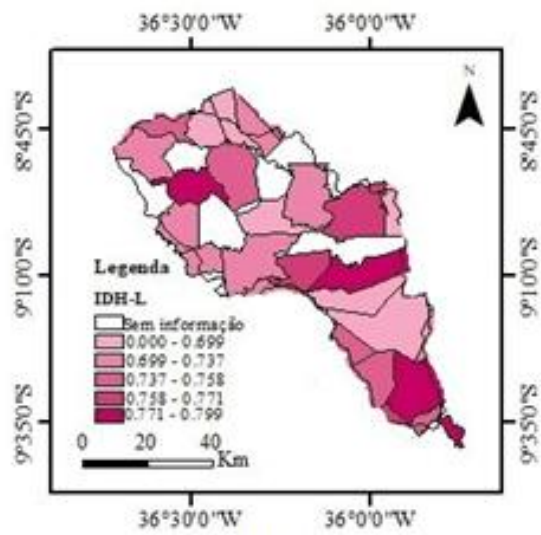

(d)

Figura 5 - Distribuição espacial do Índice de Desenvolvimento Humano Municipal, Índice de Desenvolvimento Humano educacional, Índice de Desenvolvimento Humano Renda, e Índice de Desenvolvimento Humano Longevidade nos municípios que compõe a bacia do Rio Mundaú. Fonte: Sistema Integrado de Informações sobre Desastres (S2ID)-2018.

Em relação aos parâmetros IDH-E, IDH-R e IDH-L, verifica-se a alta similaridade com o IDH-M e grande similaridade estética entre os mapas. É oportuno ressaltar entre as regiões da bacia que para a região norte-oriental da bacia os municípios de Caetés-PE, Jurema-PE e São João-PE e na porção central os municípios de Correntes-PE, Lagoa do Ouro-PE e Ibateguara-AL e na porção sul Branquinha-AL e Murici-AL apresentam os piores índices de IDH-E, evidenciando os contrastes sociais e econômicos existentes nesses municípios. Skidmore e Toya (2002), identificaram em seu estudo que a correlação entre países desenvolvidos e com alta taxa de escolaridade, maior abertura econômica e menor atuação do governo na economia, acabam por ter em média um menor nível de mortes e danos materiais devido a desastres naturais.

\section{2 ÍNDICES DE RISCO E DE VULNERABILIDADE}

Verifica-se na Figura 6 a distribuição espacial do risco a desastre e de vulnerabilidade dos municípios, cujos riscos Baixo e Alto estão presentes em maior quantidade em risco a desastres. Destaca-se o município de Maceió - $A L$, cujo valor de risco foi verificado a 0.051-1.00, em virtude dos casos de 
transbordamento de rios, deslizamento de encostas, desabamento de casa, inundações, chuvas intensas, pontos de alagamentos e população em áreas de risco, representando o único município com valor muito alto a desastre e o município de Garanhuns-PE com risco à desastre alto com valor variando entre 0.029 -0.049. Quando estas ocupações ocorrem de forma desordenada, em trabalho realizado por Aragão et al. (2017) ao analisar a densidade populacional e o impacto do crescimento populacional sobre o escoamento simulado, observou-se que diversos impactos são ocasionados, dentre elas a impermeabilização que se reflete sobre o saneamento ambiental e sobre as águas urbanas e seu sistema de drenagem.

Para o cenário de vulnerabilidade observado na Figura $6 \mathrm{~b}$, praticamente todos os municípios se encontram em grau de vulnerabilidade que varia de moderada a muito alta, destacando os municípios de Garanhuns-PE, União dos Palmares-AL, Atalaia-AL, Lajedo-PE, Rio Largo-AL e Pilar-AL que obtiveram grau de vulnerabilidade muito alta virando de 0.023 - 1.000 e Alta os municípios de Capoeiras-PE, Caetés-PE, São João-PE, Canhotinho-PE, São José da Laje-AL e Murici-AL, com valores de $0.013-0.022$.

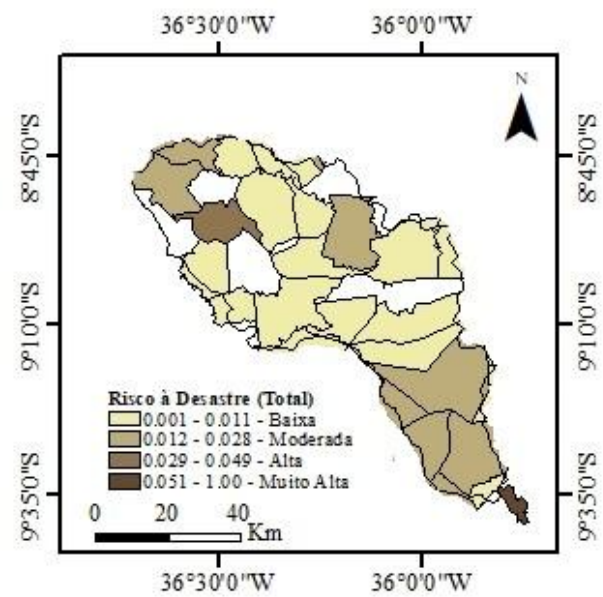

(a)

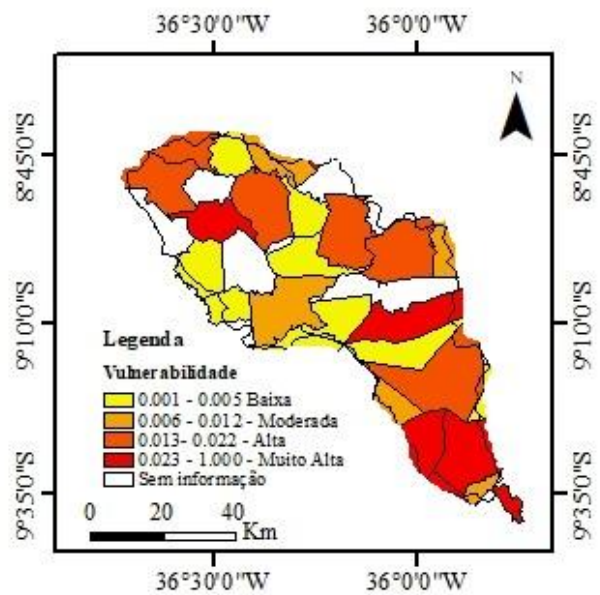

(b)

Figura 6- Distribuição espacial do índice de risco e de vulnerabilidade a desastres dos municípios que compõe a bacia hidrográfica do rio Mundaú para o período de 1963 a 2017. Fonte: Sistema Integrado de Informações sobre Desastres (S2ID)-2018.

Estes riscos em aplicação de Mateus (2014), ao ser vinculado à exposição a extremos são diversos e tem relação direta com a vulnerabilidade das populações à magnitude dos eventos, visto que agravam os problemas e afetam a vida social ao acentuarem à exposição das populações mais vulneráveis.

Quanto ao risco de desastre às chuvas (Figura 7a), observa-se que a região sul da bacia apresenta índices que variam de moderada (0.013-0.028) a muito alta $(0.108-1.00)$, enquanto que para a região central e norte-oriental da bacia apresentam pontos isolados de alto risco a desastre no período chuvoso, sendo mais dominante o baixo risco. Ao observar estes dados, observa-se que o município de Maceió-AL que apresenta índice a desastre muito alto para o período chuvoso, foi observado por Moura et al. (2016), neste este município os eventos excepcionais de chuva deflagram desastres geológicos do tipo deslizamento e escorregamento, devido à ocupação habitacional irregular, principalmente, habitações pertencentes à população mais pobre que se 
localizam nas vertentes dos tabuleiros e das colinas de litologia sedimentar da Formação Barreiras.

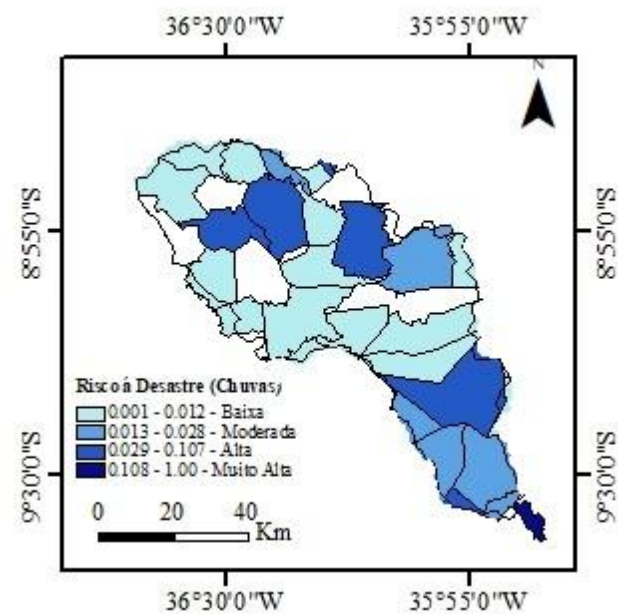

(a)

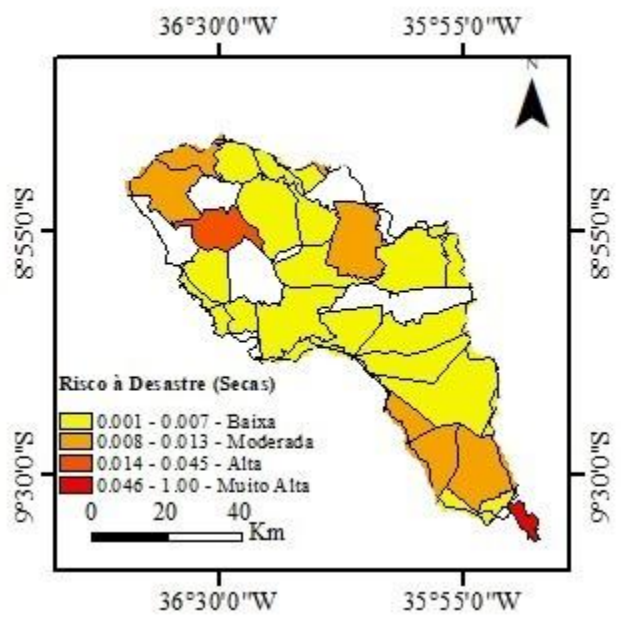

(b)

Figura 7- Distribuição espacial do índice de risco a desastres de chuva (a) e risco a desastre de seca (b) dos municípios que compõe a bacia hidrográfica do rio Mundaú para o período de 1963 a 2017.Fonte: Sistema Integrado de Informações sobre Desastres (S2ID)-2018.

Ainda analisando a figura $7 \mathrm{~b}$ verifica-se que os riscos à desastres no período seco é mais uniforme em toda a bacia, sendo ocasionado de maneira Alta apenas em Garanhuns-PE (0.014-0.045) e muito Alta em Maceió-AL (0.046-1.00). Em estudo elaborado por Olímpio (2013) e Barbieri (2014), este fato é respondido pela circunstância em que cidades do semiárido estão inseridas, onde, os predomínios do clima mais quente e seco ocorrem registros de desastres naturais do tipo de estiagem/seca, os eventos de chuvas intensas e extremas possuem periodicidade esporádica, que por sua vez, podem deflagrar desastres hidrometeorológicos com danos comparados aos danos gerados de estiagem e seca.

\subsection{CENÁRIOS CLIMÁTICOS DA PRECIPITAÇÃO PLUVIOMÉTRICA}

Os cenários climáticos futuros da precipitação são observados na Figura 8 para os anos de 2025 e 2055, apresentando em (a) as normais climatológicas da precipitação para o período de 1960 à 1991 referida como Baseline, enquanto que os cenários para 2025 se apresentam em (b) ETA-Low, (c) ETAMidi, (d) ETA-High correspondente a baixa, média e alta sensibilidade do modelo, respectivamente, enquanto que para o ano de 2055 estão expressos em (e) ETA-Low, (f) ETA-Midi e (g)ETA-High, seguindo a mesma ordem de sensibilidade do modelo. 


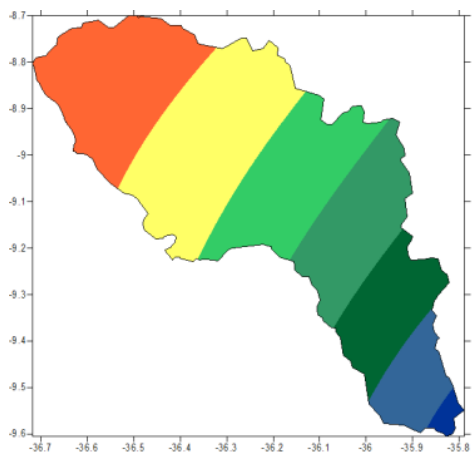

(a) Baseline

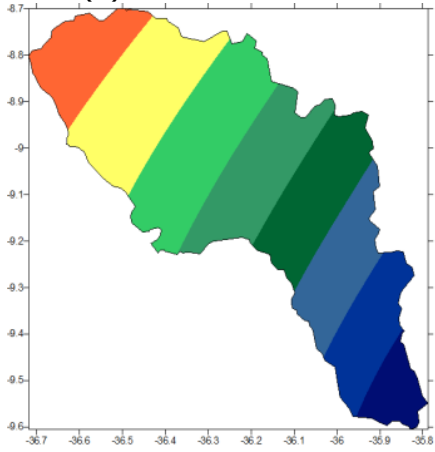

(c) ETA- Midi 2025

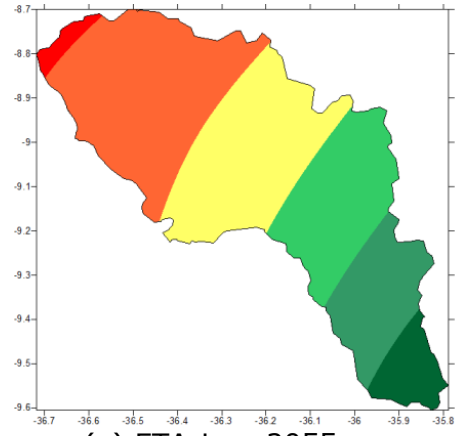

(e) ETA-Low 2055

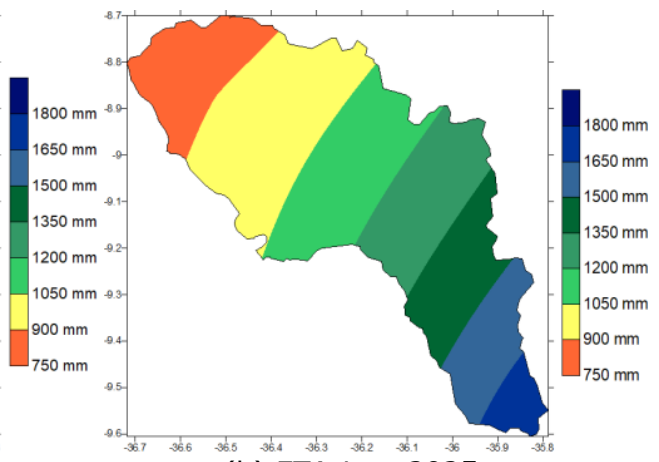

(b) ETA-Low 2025

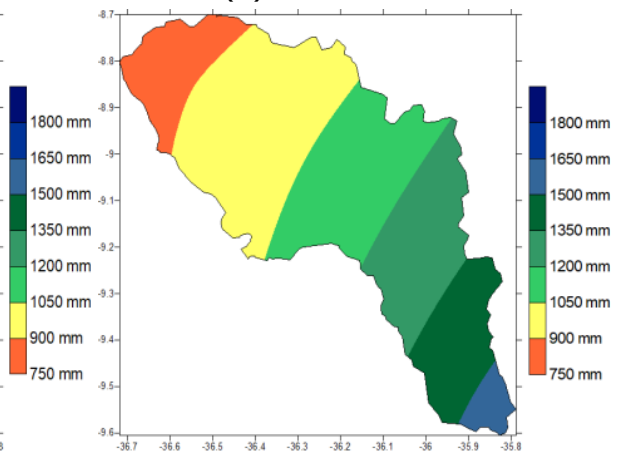

(d) ETA-High 2025

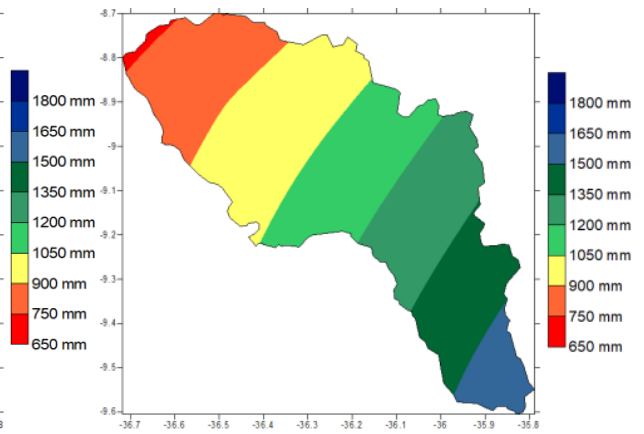

(f) ETA-Midi 2055

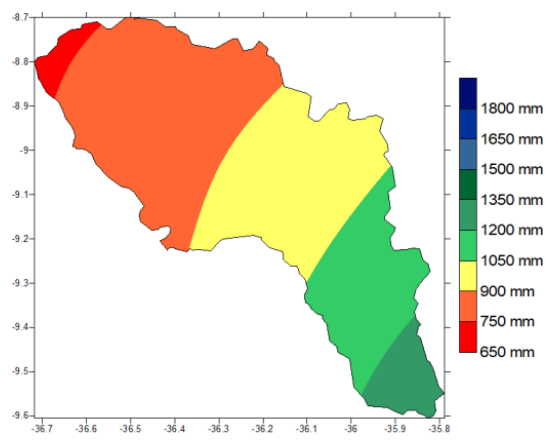

(g) ETA - High 2055

Figura 8 - Cenários climáticos da precipitação pluviométrica anual para os anos de 2025 e 2055 para a bacia hidrográfica do rio Mundaú.

A Baseline observada na figura, expressa um cenário climático de elevados índices de precipitação em toda região sul e central, que compreendem 
à zona baixa e média da bacia, variando de 1800 a $1500 \mathrm{~mm}$ anuais. A área norte-oriental da bacia apresenta baixos índices de precipitação anual, variando de $950 \mathrm{~mm}$ a $750 \mathrm{~mm}$ anuais em (a) Baseline.

Salienta-se que a diferença abruta nos valores das precipitações em uma mesma bacia hidrográfica em que não representam nenhum limite físico para a transição das condições naturais de uma região para outra deve-se principalmente pelo fato de que esta bacia apresenta em sua zona baixa, aproximação entre a Mata Atlântica e a medida que se aproxima da região Agreste.

Verifica-se que os cenários ETA-Low (b), e ETA-High(d) para o ano de 2025, demostram uma tendência de diminuição da precipitação no sul da bacia em que a precipitação varia de $1650 \mathrm{~mm}$ a $1800 \mathrm{~mm}$ e $1500 \mathrm{~mm}$ respectivamente. Ao observar o norte-oriental que compreende a zona alta da bacia, o modelo ETA-High apresenta alterações significativas em que ocorre o aumento das áreas que a precipitação diminuirá. Já o cenário otimista para região é observado no ETA-Midi que a área correspondente ao sul da bacia (que para os outros modelos uma pequena parte variava entre $1650 \mathrm{~mm}$ à 1800 $\mathrm{mm}$ ), ocorreu uma maior abrangência. O mesmo é observado para o Agreste em que o maior domínio de precipitação para os demais modelos são precipitações de $900 \mathrm{~mm}$ e a área que compreende $750 \mathrm{~mm}$, houve uma diminuição.

Os cenários ETA-Low (e), ETA-Midi (f), e ETA-High ( $g$ ), configuram-se em perspectivas menos otimistas para os extremos da bacia. O modelo ETA-Low (e) demostra diminuição dos índices de precipitação, em que uma área que compreendia um volume de $750 \mathrm{~mm}$ a $900 \mathrm{~mm}$ em 2025, para o ano de 2055 as precipitações não passariam de $750 \mathrm{~mm}$, evidencia uma presença nesse modelo para o surgimento de uma pequena área com a presença de $650 \mathrm{~mm}$. A mesma diminuição marcante é encontrada para o sul da bacia para o mesmo modelo, em que a precipitação que variava de 1500 a $1800 \mathrm{~mm}$, para o ano de 2055 para esta área não ocorreria um volume maior que $1350 \mathrm{~mm}$.

O ETA-Midi (f) para o ano de 2055 exibe o cenário mais otimista para a região sul da bacia e menos pessimista em comparação aos demais modelos para o norte-oriental da bacia em que a precipitação varia de 1500 a 1200 até a área central da bacia. O ETA-High ( $\mathrm{g}$ ) se mostrou o pior índice de precipitação para a bacia no ano de 2055 ocorrendo uma expansão das áreas mais secas, apresentando precipitações que variam de $650 \mathrm{~mm}$ a $1350 \mathrm{~mm}$. Evidencia neste modelo que áreas úmidas como a região sul da bacia que apresenta sistemas atmosféricos dominantes, apresenta tendência à aridização.

Os cenários climáticos da precipitação anual para os anos de 2025 e 2055 em sua alta, média e baixa sensibilidade (exceto o ETA-Midi para 2025), exibem um aumento relevante da abrangência de áreas dos baixos índices de precipitação pluviométrica, representando uma perspectiva desafiadora para o desenvolvimento de diversas atividades desenvolvidas na bacia.

Os métodos de aplicabilidade de previsão da precipitação com o objetivo de aumentar a representatividade dos processos em mesoescala. Em trabalho realizado por Silva (2012), a confiabilidade dos modelos regionais e sua precisão dependem da qualidade da condição de contorno lateral e da sua capacidade do modelo regional de desenvolver características reais do clima em estudo, 
enquanto que para Santiago (2015), ao elaborar estudo para a Zona da Mata de Pernambuco, os modelos climáticos são influenciados também por diferentes fenômenos atmosféricos, além da ocorrência de diferença escala espacial entre os valores simulados e observados. Em contrapartida, Valverde e Marengo (2010), relatam que os modelos climáticos globais ainda não conseguem reproduzir com alta confiabilidade o padrão sazonal de precipitação quando comparado com a climatologia observada.

\section{CONSIDERAÇÕES FINAIS}

Os maiores registos dos impactos dos eventos extremos foram as estiagens, enxurradas, secas, inundações e alagamentos, sendo os eventos de secas concentrados na região semiárida e os de chuva próximos ao litoral da bacia do qual, estes eventos extremos resultaram em danos irreparáveis.

Observou-se que para os índices de desenvolvimento os maiores índices de IDH-M foram encontrados na porção sul da bacia do rio Mundaú, enquanto os piores índices pontos isolados. Para os parâmetros IDH-E, IDH-R e IDH-L, verificou-se alta similaridade com o IDH-M. Os municípios localizados no norte/noroeste e na porção sul da bacia apresentaram os piores índices de IDHE, evidenciando os contrastes sociais e econômicos existentes nessas regiões.

Com relação ao mapeamento dos índices de risco a desastres e de vulnerabilidade, as regiões sul/sudeste e extremo norte/noroeste apresentam risco a desastres moderado a muito alto em relação aos eventos extremos, bem como vulnerabilidade alta a muito alta nessas regiões e em algumas localidades da área central da bacia, evidenciando que os eventos extremos de precipitação (chuvas intensas e secas) tem relação direta com a vulnerabilidade das populações da bacia, afetando as condições socioeconômicas e ambientais, e consequentemente a qualidade de vida na região. Este resultado é também encontrado para os cenários climáticos para os anos de 2025 e 2055 da precipitação que indicaram diminuição dos totais anuais.

O conhecimento destes índices permite em bacias hidrográficas com diferentes usos do espaço urbano e rural, agregar com informações, auxiliando em tomada de decisões dos atores públicos e comunitários, maximização a produção rural além de impedir pontos de alagamentos e de deslizamentos de encostas.

Apesar destas alterações observadas no presente estudo, não pode ser afirmado que as tendências destes índices estão relacionadas apenas às mudanças climáticas globais, visto que a bacia do Rio Mundaú apresenta históricos que podem ter modificado o clima da região, como por exemplo, a substituição de áreas vegetadas por asfaltos, desmatamento e urbanização acelerada.

\section{REFERÊNCIAS BIBLIOGRÁFICAS}

ARAGÃO, J. A influência dos oceanos Pacífico e Atlântico na dinâmica do tempo e do clima do Nordeste do Brasil. Oceanografia-Um cenário tropical (Eds E. Esquinazi-Leça, S. Neumann-Leitão and MF Costa.), p. 287-317, 2017. 
ALVARES, C. A.; STAPE, J. L.; S, P. C.; MORAES, G. J. L.; S, G. Köppen's climate classification map for Brazil. Meteorologische Zeitschrift, Estugarda, Alemanha, v.22, n.06, p. 711-728, 2014.

AUGUSTIN, S.; RODRIGUES, I.N.; LEONARDELLI, P.P. A influência da densidade populacional no desenvolvimento sustentável. Revista de direito brasileiro, Caxias do Sul, v. 1, p. 89-104, 2014.

BARBIERE, G. M. L. Eventos de chuva extrema associados a sistemas atmosféricos de escala sinótica e escala local no estado do Ceará. Tese (Doutorado em Geografia) - Programa de Pós- graduação em Geografia, Universidade Federal do Ceará, Fortaleza, 2014.

DE ARAújo SILVA, S., Candeias, A. L. B., Gomes, D. D. M., \& de Souza, W. M. Variabilidade espaço-temporal da precipitação na bacia hidrográfica do Rio Mundaú (PE/AL). Revista Brasileira de Climatologia, 23. 2018.

DELAZERi, L. M. M., CUNHA, D. A.; COUTO. S, F. R. Climate changeand urbanization: Evidence from the semi-arid region of Brazil.Revista Brasileirade Estudos Regionais e Urbanos, V. 12 p.129-154. 2018.

FREITAS, C. M. D.; CARVALHO, M. L. D.; XIMENES, E. F.; ARRAES, E. F.; GOMES, J. O. Vulnerabilidade socioambiental, redução de riscos de desastres e construção da resiliência: lições do terremoto no Haiti e das chuvas fortes na Região Serrana, Brasil. Revista Ciência \& Saúde Coletiva, v.17, p.1577-1586, 2012.

FREITAS, C. M. et al. Desastres naturais e saúde: uma análise da situação do Brasil. Ciência \& Saúde Coletiva, v. 19, n. 9, p. 3645-3656, 2014.

Gomes, D. D. M., de Lima, D. R. M., Veríssimo, C. U. V., \& Duarte, C. R. Mapeamento e caracterização dos sistemas ambientais da bacia hidrográfica do Rio Mundaú-PE/AL. Caderno de Geografia, v. 26(2), p 272-299. 2016.

GOMES, D. D. M.; DE LIMA, D. R. M.; DUARTE, C. R.; VERÍSSIMO, C. U. V.; GOLDFARB, M. C. Análise e Compartimentaçã Moformétrica da Bacia Hidrográfica do Rio Mundaú - Pernambuco e Alagoas. Revista de Geologia, Fortaleza, v.27, n2, p.167-182, 2014.

HAGENLOCHER, M., MEZA, I., ANDERSON, C. C., MIN, A., RENAUD, F. G., WALZ, Y.; SEBESVARI, Z. Drought vulnerability and risk assessments: state of the art, persistent gaps, and research agenda. Environmental Research Letters, v. 14(8). 2019.

LACERDA, F.; FERREIRA, M. A.F.; SOUZA, W.M. Climas do Estado de Pernambuco In: Bacias Hidrográficas de Pernambuco. Recife. Comunigraf Editora, p. 16-17, 2006.

LUQUE, G. M.; HOCHBERG, M. E.; HOLYOAK, M.; HOSSAERT, M.; GAILL, F.; COURCHAMP, F., 2013. Ecological effects of environmental change. Ecology Letters,v. 16, n. s1, p. 1-3, 2013.

MARENGO, J. A.; CUNHA, A. P.; \& ALVES, L. M. A seca de 2012-15 no semiárido do Nordeste do Brasil no contexto histórico. Climanálise, v. 3, p. 49-54, 2016.

MARENGO, Jose A. Vulnerabilidade, impactos e adaptação à mudança do clima no semi-árido do Brasil. Parcerias estratégicas, v. 13, n. 27, p. 149-176, 2010. 
MATEUS, K.P.P. Ondas de calor e ondas de frio em Coimbra: impactes na mortalidade da população. Master's thesis. 2014.

MOURA, M. O., C, C., NÓBREGA, R. S., \& DUARTE, C. C. Desastres hidrometeorológicos na região Nordeste do Brasil: distribuição espaço-temporal dos reconhecimentos de Estado de Calamidade Pública. Caderno de Geografia, v. 26(2), p.259-271. 2016.

MOURA, M. O.; CUNICO, C.; NÓBREGA, R. S.; DUARTE, C. C. Desastres hidrometeorológicos na região Nordeste do Brasil: distribuição espaço-temporal dos reconhecimentos de Estado de Calamidade Pública. Caderno de Geografia, v. 26(2), p. 259-271, 2016.

MOURA, R. Gonçalves et al. Avaliação do modelo regional ETA utilizando as análises do CPTEC e NCEP. Revista Brasileira de Meteorologia, v. 25, n. 1, p. 4653, 2010.

NEUHAUS, F. Influência das mudanças climáticas no regime pluviométrico em Erechim, RS no século XXI. 2017.

NÓBREGA, R. S.; FARIAS, R. F. L.; SANTOS, C. A. C. Variabilidade temporal e espacial da precipitação pluviométrica em Pernambuco através de índices de extremos climáticos. Revista brasileira de meteorologia, v. 30, n. 2, p. 171-180, 2015.

OLÍMPIO, J. L. S; VIEIRA, P. M; ZANELLA, M. E; SALES, M. C. L. Episódios Pluviais Extremos e a Vulnerabilidade Socioambiental do município de Fortaleza: o episódio do dia 27/03/2012. Revista Geo. v. 1, n. 24, p. 181 - 206, 2013.

OYAMA, M. D., C. A. NOBRE.. A new climate-vegetation equilibrium state for Tropical South America. Geophysical Research Letter, v. 30, n. 23, p. 2199, 2003.

RAMOS, C. S.; SANCHEZ, M. C. Estudo metodológico de classificação de dados para cartografia temática. Geografia, v. 25, n. 2, p. 23-52, 2000.

SANTIAGO, G. A. C. F. Impactos de cenários climáticos futuros na aptidão agroclimática da cana-de-açúcar na Zona da Mata de Pernambuco. 2015.

SILVA, D. F.; ARAÚJO, L. E.; KAYANO, M. T.; SOUSA, F. A. S. Análise da precipitação na bacia do rioMundaú usando o IAC. Revista UNOPAR, Curitiba, v. 07, n. 03, p. 53-61, 2008.

SILVA, R. O. B.; MONTENEGRO, S. M. G. L.; SOUZA, W. M. Tendências de mudanças climáticas na precipitação pluviométrica nas bacias hidrográficas do Revista Brasileira de Climatologia. Vol. 28-JAN/JUN 2021390estado de Pernambuco. Engenharia Sanitária e Ambiental, v. 22, n. 3, p. $579-589,2017$.

SILVA, W. L. Tendências Observadas e Projeções Futuras de Extremos Climáticos na Cidade do Rio de Janeiro. Monografia. Universidade Federal do Rio de Janeiro, Departamento de Meteorologia. XVIII, 85 p. Rio de Janeiro, 2012.

SKIDMORE, M. AND TOYA, H. Do natural Disasters Promote the Long Run Growth?. Economic Inquire, vol 40(4), p.p. 664-687. 2002. 
TAVARES, V. C., DE ARRUDA, Í. R. P., \& DA SILVA, D. G. Desertificação, mudanças climáticas e secas no semiárido brasileiro: uma revisão bibliográfica. Geosul, V.34(70), P.385-405. 2019.

VALENCIO, N. ; MARCHEZINI, V.;LINDELL, Michael K. and PERRY, R. W. Communicating environmental risk in multiethnic communities. California: Sage Publications Inc: 246 p. UFScar. São Carlos, 2004.

VALENCIO, N.F.L.S. Chuvas no Brasil: representações e práticas sociais. Florianópolis. Revista Política e Sociedade v4, p. 163-183, 2005. 